\title{
Immune response of lambs experimentally infected with Haemonchus contortus and parenterally treated with a combination of zinc and copper
}

\author{
A.S. Schafer ${ }^{\mathrm{a}, *}{ }^{*}$, M.L.R. Leal ${ }^{\mathrm{b}}$, M.B. Molento $^{\mathrm{c}}$, A.R. $^{\text {Aires }}{ }^{\mathrm{b}}$, M.M.M.F. Duarte $^{\mathrm{d}}$, \\ F.B. Carvalho ${ }^{f}$, A.A. Tonin ${ }^{\mathrm{a}}$, L. Schmidt ${ }^{\mathrm{e}}$, E.M.M. Flores ${ }^{\mathrm{e}}$, R.T. França ${ }^{\mathrm{a}}$, \\ T.H. Grando ${ }^{g}$, A.P. Minho ${ }^{\text {, }}$ A. Krause ${ }^{a}$, A.Q. Antoniazzi ${ }^{b}$, S.T.A. Lopes ${ }^{a}$ \\ a Laboratório de Análises Clínicas Veterinárias, Departamento de Clínica de Pequenos Animais, Universidade Federal de Santa Maria, \\ Santa Maria, Brazil

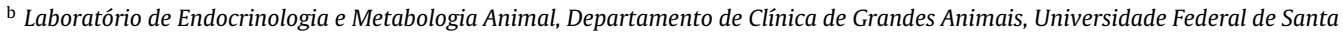 \\ Maria, Santa Maria, Brazil \\ c Laboratório de Doenças Parasitárias, Universidade Federal do Paraná, Curitiba, Brazil \\ d Universidade Luterana do Brasil, Santa Maria, Brazil \\ e Laboratório de Química Industrial e Alimentar, Universidade Federal de Santa Maria, Santa Maria, Brazil \\ f Setor de Bioquímica e Estresse Oxidativo do Laboratório de Terapia Celular, Universidade Federal de Santa Maria, Santa Maria, Brazil \\ ${ }^{g}$ Laboratório de Parasitologia Veterinária, Universidade Federal de Santa Maria, Santa Maria, Brazil \\ h Empresa Brasileira de Pesquisa Agropecuária, Embrapa Pecuária Sul, Bagé, Brazil
}

\section{A R T I C L E I N F O}

\section{Article history:}

Received 15 May 2014

Received in revised form 27 October 2014

Accepted 29 October 2014

Available online 7 November 2014

\section{Keywords:}

Haemonchus contortus

Sheep

Lambs

Minerals

Immunology

\begin{abstract}
A B S T R A C T
Haemonchus contortus parasite causes high mortality rates and drastic productivity reduction besides enhancing treatment costs. It has also been demonstrating great resistance against most of the drugs currently in use. Thus, the utilization of elements that can boost the host immune response to cope with the infection has been widely studied. Some researchers have shown that the use of zinc $(\mathrm{Zn})$ and copper $(\mathrm{Cu})$ as nutritional supplements can help controlling the parasites. The present study evaluated the immune response of lambs experimentally infected with $\mathrm{H}$. contortus and treated with $\mathrm{Zn}$ and $\mathrm{Cu}$. Twenty-one (21) lambs were divided into three groups: CG (non-infected control group), IG (infected group - infection performed with 15,000 larvae of $H$. contortus/animal) and ITG (group infected and treated subcutaneously with $1.5 \mathrm{mg} / \mathrm{kg}$ of $\mathrm{Zn}$ and $0.45 \mathrm{mg} / \mathrm{kg}$ of Cu on days 10 and 45 post-infection [PI]). Blood samples were drawn on days $0,14,28,42,56$ and $70 \mathrm{PI}$ in order to determine the serum concentrations of interleukin 1 (IL-1), interleukin 4 (IL-4) and interleukin 6 (IL-6), interferon-gamma (IFN- $\gamma$ ), tumor necrosis factor-alpha (TNF- $\alpha$ ) and immunoglobulins (Igs) IgA, IgE, IgG and IgM. The parasitic infection was monitored by the counting of eggs per gram of feces (EPG) in the same intervals of blood sampling. At the end of the experiment, animals were euthanatized and the parasite load was quantified. In addition, the concentrations of $\mathrm{Zn}$ and $\mathrm{Cu}$ in liver were assessed. A significant increase in EPG was observed only on day 14 PI for IG and ITG $(P<0.05)$. Between days 14 and 42 there was a significant increase $(P<0.001)$ of cytokine and immunoglobulin levels in IG and ITG, when compared with the animals of CG. After day 56, the IG animals showed serum level of interleukins and immunoglobulins lower than ITG animals $(P<0.001)$. Regarding the liver
\end{abstract}

\footnotetext{
* Corresponding author at: Laboratório de Análises Clínicas Veterinárias, Departamento de Clínica de Pequenos Animais, Universidade Federal de Santa Maria, Avenida Roraima 1000, 97105-900 Santa Maria, Rio Grande do Sul, Brazil. Tel.: +55 9994 9003; fax: +55 3220 8814.

E-mail address: andressasalvadori@hotmail.com (A.S. Schafer).
} 
concentrations of $\mathrm{Zn}$ and $\mathrm{Cu}$, the infection showed to lead a depletion of these minerals; therefore, the supplementation did not prevent this effect. The results of this study indicate that the administration of $\mathrm{Zn}$ and $\mathrm{Cu}$ was capable of enhancing the immune response in lambs experimentally infected with $H$. contortus. However, it did not reduce egg counts in the feces or the number of adult parasites in the abomasum.

(c) 2014 Elsevier B.V. All rights reserved.

\section{Introduction}

The gastrointestinal parasite Haemonchus contortus is the major cause of production losses in small ruminants (Bambou et al., 2009). It has parasitic activity on the abomasum mucosa, usually causing spoliation due to its hematophagous behavior. This spoliation may lead to severe anemia, weight loss, and high mortality (Amarante, 2001). H. contortus induces the innate and adaptive immune responses, which are essential for the clearance of this nematode of the host (Meeusen et al., 2005).

Due to high mortality rates, drastic productivity reduction, high treatment costs, and the great parasite resistance against most of the drugs currently in use (Molento et al., 2009), several studies have been carried out seeking other alternatives to reduce the frequent and indiscriminate use of anthelmintic drugs. The use of elements may boost the host immune response to cope with infections, which includes the administration of minerals (Soli et al., 2010). $\mathrm{Zn}$ and $\mathrm{Cu}$ are known to play an important role in the animal organism (Herdt and Hoff, 2011). In addition, some researchers have shown that the use of $\mathrm{Cu}$ and other minerals, such as nutritional supplements may help controlling the parasites (Nicolodi et al., 2010; Fausto, 2011). However, there is still lack of studies using the combination of minerals in an attempt to provide better conditions to face the severe parasitism caused by $H$. contortus. Thus, this study aimed to evaluate the effects of the parenteral administration of $\mathrm{Zn}$ associated with $\mathrm{Cu}$ in the innate and adaptive immune responses of lambs experimentally infected with $H$. contortus through the determination of serum cytokines (IL-1, IL-4 and IL-6, IFN- $\gamma$ and TNF- $\alpha$ ) and immunoglobulins (IgA, IgE, IgG and IgM).

\section{Materials and methods}

\subsection{Experimental design}

Twenty-one crossbred (Texel and Corriedale) male lambs, eight months old and weighing an average of $17 \mathrm{~kg}$ were housed in collective pens. During the adaptation to the diet and experimental environment (20 days), all animals were treated with monepantel-base anthelmintic $2.5 \mathrm{mg} / \mathrm{kg}\left(\right.$ ZOLVIX $\left.^{\circledR}\right)$. After this adaptation period, the lambs were separated into three distinct pens and randomly divided into three groups of seven animals each: non-infected control group (CG), group infected with $H$. contortus (IG) and group infected with $H$. contortus and treated with a parenteral treatment with $\mathrm{Zn}$ and $\mathrm{Cu}$ (ITG). The experimental period lasted three months (during summer) and the animals were housed in collective pens in an Experimental area of the Department of Large Animals belonging to the Universidade Federal de Santa Maria (UFSM). The experimental protocol was approved by the Comitê de Ética no Uso de Animais (CEUA) of UFSM, registration number 012/2011.

\subsection{Experimental infection}

All lambs were certified as negative to the parasite before the experimental period through the McMaster technique (Ueno and Gonçalves, 1998). The infection was carried out with three doses of 5000 infective larvae (L3) of $H$. contortus, administered orally within an interval of three days between doses, totaling 15,000 larvae per animal. The first day of the experimental infections was considered as day 0 (D0). The coproculture material was obtained from a donor lamb experimentally infected with a monospecific culture obtained from Empresa Brasileira de Pesquisa Agropecuária (EMBRAPA/Bagé/RS).

\subsection{Hematocrit}

The hematocrit was performed every 3 days in order to monitor the disease progression. The amount of $500 \mu \mathrm{L}$ of blood was collected by jugular puncture and stored in tubes with anticoagulant (EDTA 10\%). Hematocrit was measured using the standard microhematocrit method (Centmicro mod. 1-15-Sigma, Germany) according to the method of Lassen and Weiser (2007).

\subsection{Diet}

Animals were fed $1 \mathrm{~kg}$ of dry matter/day and water ad libitum. The diet containing $11 \%$ protein was composed of ryegrass hay (Lolium multiflorum) and commercial ration (Supra ${ }^{\circledR}$ ). On day $30 \mathrm{PI}$, the diet was changed in order to increase the total protein to $13 \%$. This change was performed because of the intensity of the clinical symptoms exhibited by the animals infected with $H$. contortus.

\subsection{Treatment}

The treatment was performed with Suplenut ${ }^{\circledR}$ (Biogenesis-Bagó, Buenos Aires, Argentina), according to the specifications and characteristics of the product or $1.5 \mathrm{mg}$ of Zn EDTA $/ \mathrm{kg} / \mathrm{BW}$, associated with $0.45 \mathrm{mg}$ of Cu EDTA $/ \mathrm{kg} / \mathrm{BW}$. Volumetrically, $0.033 \mathrm{~mL} / \mathrm{kg} / \mathrm{BW}$ of the compound was subcutaneously injected in the ITG animals on days 10 (D10) and 45 (D45) PI.

\subsection{Sampling}

Blood samples were drawn by jugular puncture, using vacuum tubes without anti-coagulant, on days 0 (D0), 14 (D14), 28 (D28), 42 (D42) 56 (D56) and 70 (D70) PI. At the same experimental periods, fecal samples were collected (directly from the rectum) to perform the counting of eggs per gram of feces (EPG), using the McMaster method. Immediately after the last sampling collection, five animals from each group were euthanized (protocol: $10 \mathrm{mg}$ acepromazine $2 \%$, intravenous [IV]; $2 \mathrm{~g}$ of thiopental sodium [IV] and $100 \mathrm{~mL}$ of potassium chloride intravenous [IV]) in order to determine the parasite load (Ueno and Gonçalves, 1998). Fragments of liver tissue were also collected to assessment of $\mathrm{Zn}$ and $\mathrm{Cu}$ concentrations.

\subsection{Evaluated parameters}

\subsubsection{Serum cytokines and immunoglobulins}

Serum cytokines (IL-1, IL-4, IL-6, TNF- $\alpha$ and IFN- $\gamma$ ) were quantified by ELISA, using commercial kits (Bioscience, San Diego, EUA). Serum immunoglobulin (IgG, IgM, IgA and $\operatorname{IgE}$ ) was determined by standard nephelometry, using commercial kits (Dade Behring Diagnostic, Marburg, Germany) and following the manufacturer's instructions. The commercial kits used were previously standardized for sheep. 
2.7.2. Determination of hepatic concentrations of $\mathrm{Zn}$ and $\mathrm{Cu}$

Concentrations of $\mathrm{Zn}$ and $\mathrm{Cu}$ were determined by optical emission spectrometry with inductively coupled plasma (ICP-OES) in a PerkinElmer spectrometer (Optima 4300 DV) (Bizzi et al., 2014).

\subsection{Statistical analysis}

Concentrations of cytokines, immunoglobulins, $\mathrm{Zn}$ and $\mathrm{Cu}$ were subjected to one-way analysis of variance (ANOVA), followed by post hoc Student Newman-Keuls test. Data of parasitic load and EPG were submitted to Kruskal-Wallis test, a variation of the non-parametric one-way ANOVA, followed by the post hoc Tukey test. The significance level was considered as 5\% $(P<0.05)$. Interleukins, immunoglobulins, $\mathrm{Zn}$ and $\mathrm{Cu}$ were shown as means and standard deviation. EPG and parasite load are expressed as median \pm interquartile range. Statistical analyzes were performed with the statistical software Graphpad Prism 5.0.

\section{Results}

\subsection{Cytokines}

Fig. 1 shows the serum levels of IL-1 (A), IL-4 (B), IL6 (C), TNF- $\alpha$ (D) and IFN-y (E) throughout the 70 days of the experiment. A significant increase $(P<0.001)$ in the levels of IL-1, IL-4, IL-6, TNF- $\alpha$ and IFN-y in IG animals was observed when compared with CG animals from D14 to D70 PI. Furthermore, ITG animals showed a significant increase $(P<0.001)$ in serum levels of IL-1, IL-6, TNF- $\alpha$ and IFN-y on D28 and D42, when compared with IG animals. IL4 of ITG animals significantly increased $(P<0.001)$ on D14, D28 and D42, when compared with IG animals. In addition, on D56 and D70 PI the levels of IL-1, IL-4, IL-6, IFN-y and TNF- $\alpha(P<0.05)$ were significantly lower $(P<0.001)$ in ITG animals, when compared with IG animals.

\subsection{Immunoglobulins}

Fig. 2 shows the serum levels of $\operatorname{IgM}(\mathrm{A}), \operatorname{IgG}(\mathrm{B}), \operatorname{Ig} \mathrm{A}$ (C) and $\operatorname{IgE}(\mathrm{D})$ during the 70 days of the experiment. A significant increase $(P<0.001)$ was observed in serum levels of IgM, IgG and IgA from D14 to D70 in IG. IgE levels were significantly increased $(P<0.001)$ in IG when compared with CG and ITG from D42. Regarding the IgM levels, ITG showed a significant increase $(P<0.001)$, when compared with IG on D14 and D28 PI. However, no significant reduction $(P>0.05)$ in IgM levels was observed on D56 and D70 PI. When compared with IG, ITG showed a significant increase $(P<0.001)$ in IgG levels only on D28 PI, and a significant reduction $(P<0.001)$ on D56 and D70 PI. IgA levels were higher in ITG, when compared with IG on D14 and D28 PI $(P<0.001)$. However, ITG showed a significant reduction $(P<0.001)$ in IgA levels on D56 and D70 PI. It was also possible to observe that in IG a significant increase $(P<0.001)$ in IgE levels occurred from D42 on, when compared with CG. ITG presented a significant increase $(P<0.001)$ in IgE levels on D14, D28 and D42 PI, in relation to CG and IG. However, the ITG showed a significant reduction in these IgE levels on D56 $(P<0.05)$ and D70 $(P<0.001)$ PI, when compared with IG.

\subsection{Parasitic load and hepatic $\mathrm{Zn}$ and $\mathrm{Cu}$}

Regarding parasitic load, we observed that the IG showed a significant increase in the number of parasites in relation to CG $(P<0.05)$; however ITG did not show a significant difference when compared with IG and CG. IG showed a significant reduction in $\mathrm{Cu}(P<0.05)$ and $\mathrm{Zn}(P<0.05)$ levels when compared with CG. No differences for hepatic $\mathrm{Zn}$ and $\mathrm{Cu}$ were observed comparing ITG with CG and IG.

Animals of CG remained EPG negative throughout the experimental period, while animals of IG and ITG showed a significant EPG increase compared with $C G(P<0.05)$, confirming our experimental infection. On the other hand, no significant differences were observed between IG and ITG.

\subsection{Macroscopic analysis of the abomasum}

The presence of $H$. contortus in the abomasal mucosa of IG and ITG lambs was observed. Macroscopic examination showed erythematous areas. IG and ITG animals showed no statistical difference regarding the parasite load.

\section{Discussion}

The present study was designed in order to assess the effect of treatment with $\mathrm{Zn}$ and $\mathrm{Cu}$ compounds on inflammatory markers and parasitic load. Lambs were used as the experimental model and were experimentally infected with $H$. contortus. The experimental infection triggered an increased production and secretion of pro-inflammatory cytokines as well as of anti-inflammatory immunoglobulins. This pattern remained during the 70 experimental days. Furthermore, a different behavior in the levels of interleukins and immunoglobulins was observed for each administration of $\mathrm{Zn}$ and $\mathrm{Cu}$. The experimental infection was able to reduce the hepatic levels of $\mathrm{Cu}$ and $\mathrm{Zn}$; however, no significant decrease was observed for the parasitic load in response to this treatment.

In our study, the first administration of $\mathrm{Zn}$ and $\mathrm{Cu}$ promoted a greater production of interleukins and immunoglobulins, while the second administration allowed observing a more positive response against the parasite by reducing the content of these inflammatory markers in the animals. According to Oliveira et al. (2011), cytokines are necessary mediators to drive the local inflammatory response to the infection and injury locations, allowing a proper healing. However, the exacerbated and persistent production of pro-inflammatory cytokines may contribute to aggravate the organ damage leading to multiple organ failure and death.

The increase in serum cytokines was observed from D14 until the end of experiment, with a gradual increase in their serum levels. Cytokine production usually occurs due to the immune stimulation, here triggered by the presence of $H$. contortus in the abomasum. The first administration of $\mathrm{Zn}$ and $\mathrm{Cu}$ was unable to oppose the cytokine increase production induced by the infection. The cytokines remained in high levels, and in some periods, their production was even higher in ITG than in IG. Peixoto et al. (1994) reported that under high stress conditions, $\mathrm{Zn}$ is a crucial element for the immune system in order to strengthen the defense mechanisms. $\mathrm{Cu}$ and $\mathrm{Zn}$ have an excellent protective effect on the synergism of the immune response ( $\mathrm{Zi}$ et al., 2009).

An increase in pro-inflammatory (IL-1, IL-6, TNF- $\alpha$ and IFN-y) and anti-inflammatory (IL-4) cytokines was also 

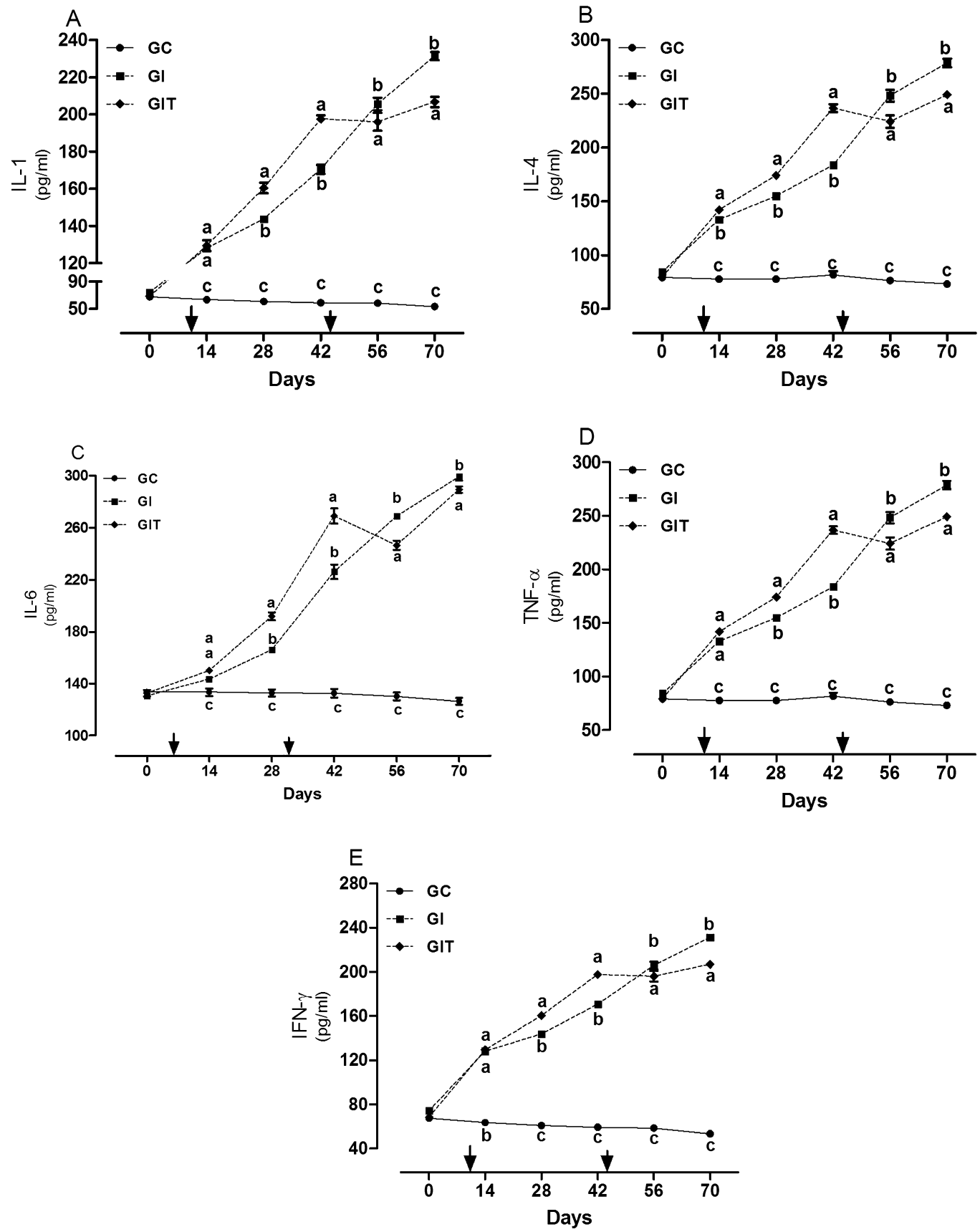

Fig. 1. Serum levels of IL-1 (A), IL-4 (B), IL-6 (C), TNF- $\alpha$ (D) and IFN- $\gamma$ (E) of lambs experimentally infected with Haemonchus contortus and treated with a commercial compound (zinc [ $1.5 \mathrm{mg} / \mathrm{kg}]$ and copper [ $0.45 \mathrm{mg} / \mathrm{kg}]$ ) on days 10 and 45 PI. Arrows indicate the time of compound administration. Different letters represent statistical difference between the CG (non-infected control group), IG (group infected with Haemonchus contortus) and ITG (infected with Haemonchus contortus and treated). One-way ANOVA followed by SNK test $(P<0.05)$, with results expressed or mean \pm SEM ( $n=7)$.

observed from D14 PI on. During severe infections, a portion of the IL-1 circulates in the bloodstream. When in combination with TNF- $\alpha$, it is in charge of the clinical manifestation causing fever, lethargy, and loss of appetite (Abbas et al., 2012), which were some clinical signs observed in some animals of this experiment. The second $\mathrm{Zn}$ and $\mathrm{Cu}$ dose reduced TNF- $\alpha$, which possibly drove the animals to a faster recovery, as well as to a reduction of the clinical manifestations. IL- 4 induces the differentiation of B-lymphocytes to produce IgE and IgG, which are important immunoglobulins in allergic and anti-helminth responses. IL-4 also acts on activated macrophages and reduces the effects of IL- 1 , TNF- $\alpha$ and IL6 , inhibiting the production of free radicals (Oliveira et al., 2011). IgM reached its peak on D42 PI. This is the most important immunoglobulin produced during the primary 

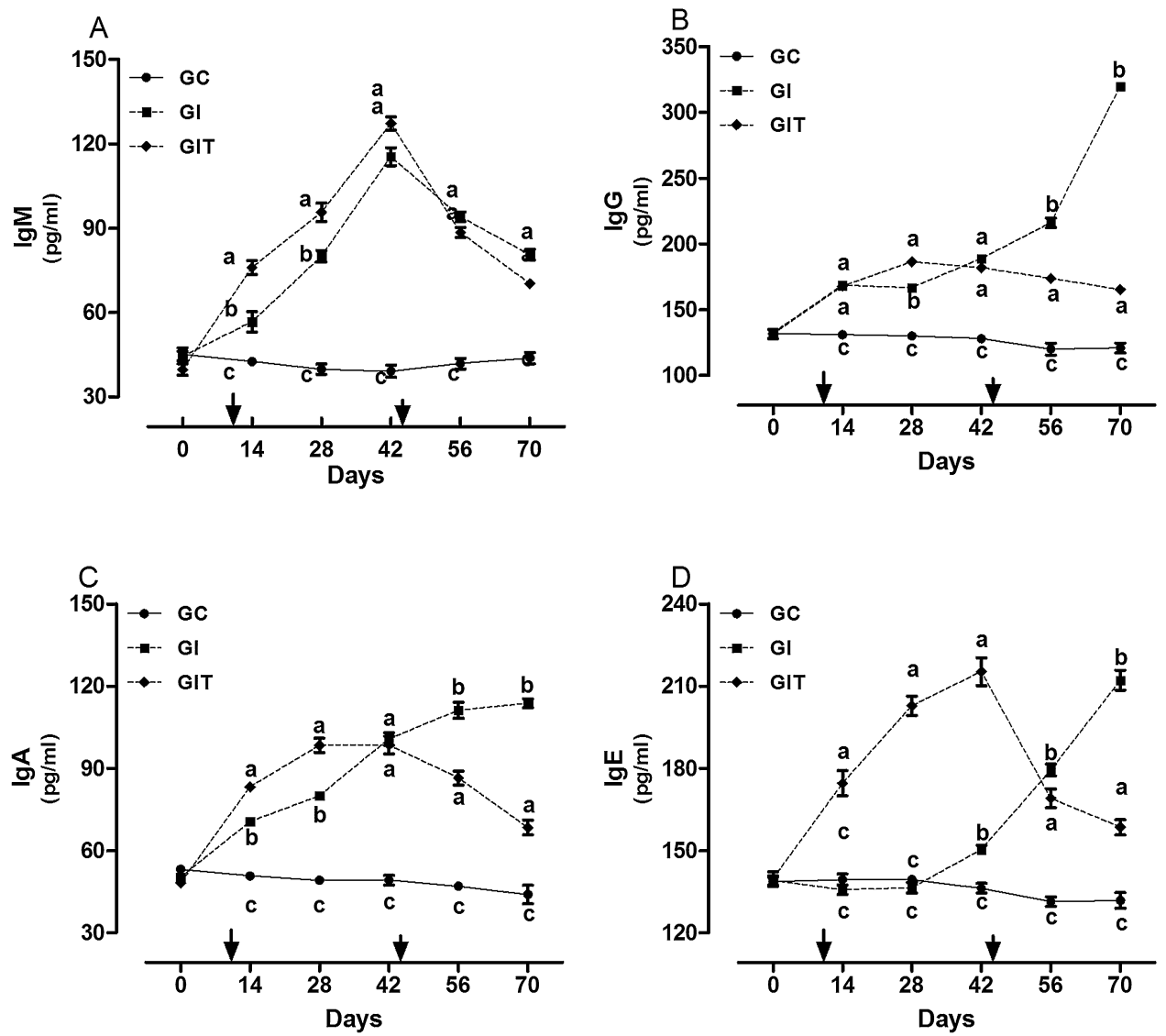

Fig. 2. Serum levels of IgM (A), IgG (B), IgA (C) and IgE (D) of lambs experimentally infected with Haemonchus contortus and treated with a commercial compound (zinc [ $1.5 \mathrm{mg} / \mathrm{kg}]$ and copper $[0.45 \mathrm{mg} / \mathrm{kg}]$ ) on days 10 and 45 PI. Arrows indicate the time of compound administration. Different letters represent statistical difference among the CG (non-infected control group), IG (group infected with Haemonchus contortus) and ITG (infected with Haemonchus contortus and treated). One-way ANOVA followed by SNK test $(P<0.05)$, with results expressed or mean \pm SEM $(n=7)$.

immune response, being capable of activating the complement effectively, which contributes to efficient infection control (Molinaro et al., 2009). From D42 PI on, IgM levels decreased gradually, demonstrating that the acute phase of infection with $H$. contortus was reached about 40 days after the animals were exposed to the parasite.

The administration of $\mathrm{Zn}$ and $\mathrm{Cu}$ did not significantly reduce the levels of IgM in infected animals. However, the most pronounced effects of this treatment were observed regarding IgG behavior, since a severe reduction in IgG levels of the ITG animals was observed from D56 PI on when compared with IG animals. IgG peak was reached on D70 PI. It is well known that this immunoglobulin acts on different nematode infection, inducing the production (in abomasum and intestine) of extra antibodies, especially against some carbohydrates present in the larval surface of various strongyles (Bungiro et al., 2008).

The same effect was observed for serum $\operatorname{IgA}$ and $\operatorname{IgE}$, since they were reduced in response to the treatment on D56 and D70 PI. These findings may be related to the second dose administration and may result in the opposite effect of $\mathrm{Zn}$ and $\mathrm{Cu}$ compound on the production of cytokines and immunoglobulins in ITG, which were in lower levels in relation to the IG. The treatment with $\mathrm{Zn}$ and $\mathrm{Cu}$ compounds increased the production of IgE from D14 PI on; however, the infection by itself stimulated an increased production of IgE on D42 PI. The presence of $\mathrm{Zn}$ and $\mathrm{Cu}$ facilitated an immune response modulated by the production of $\operatorname{IgE}$. This early increase may have helped the animals to face the parasitic infection via eosinophils. It has been reported that $\mathrm{Zn}$ and $\mathrm{Cu}$ nanoparticles, in vitro and in vivo, are able to recruit some IgE/eosinophil response on lung (Cho et al., 2012). These findings may explain the effect of the treatment, which increased IgE levels in ITG animals even before than in IG animals. IgE plays an important immunity role against helminths (Shaw et al., 1998). According to Scott and Koski (2000), Zn deficiency reduces the concentration of IgE and IgG in rats infected with gastrointestinal nematodes. Thus, the increase in the levels of these immunoglobulins in supplemented animals may be initially a result of a better mineral supply $\mathrm{Zn}$.

The experimental infection significantly increased the number of abomasum parasites in IG and ITG, when compared with CG. Even not presenting a significant difference, ITG animals demonstrated reduced indexes of $54.75 \%$ in adult parasites, when compared with the IG animals. This possibly occurred due to the protective effect of $\mathrm{Zn}$ and $\mathrm{Cu}$. Some studies have shown that $\mathrm{Zn}$ and $\mathrm{Cu}$ are able to reduce 
the parasitic load, as described by Soli et al. (2010), who used an oral administration of 4.1 grams of $\mathrm{Cu}$ particles of slow release (COWP) in sheep. Fausto (2011) observed an antioxidant effect in lambs infected with gastrointestinal nematodes and supplemented with Se and Cu parenterally, resulting in a greater weight gain, and a significant reduction in parasite burden. However, the parasite burden in the cited study was lower than in our experiment.

In this study, a reduction of cytokines and immunoglobulins, especially from the second application of $\mathrm{Zn}$ and $\mathrm{Cu}$, demonstrated an immunomodulation on the immune system. Considering the fact that an increased and persistent production of inflammatory cytokines may lead to a pathological process, instead of only assisting to face this parasitic disease, this immunomodulation may have helped to avoid the worsening of the clinical signs in infected animals, especially in ITG. Results showed that when the second dose of $\mathrm{Zn}$ and $\mathrm{Cu}$ was administered, there was still a significant concentration of available $\mathrm{Cu}$ in the liver from D45 PI on. In sheep supplemented with different sources of $\mathrm{Zn}$, plasma concentrations of this mineral was detected until D56 PI (Vilela et al., 2011). According to Guo et al. (2011), almost all the $\mathrm{Zn}$ is sequestered at the inflammation site. This may explain why a small concentration of Zn was left as "liver deposit" in this situation. Plasma levels of $\mathrm{Cu}$ in rats were detected during 40 days after its oral administration (Pocino et al., 1991). On the other hand, $\mathrm{Cu}$ stays in the blood bound to ceruloplasmin, being available to participate in redox reactions (Ranjan et al., 2005).

The second administration of $\mathrm{Zn}$ and $\mathrm{Cu}$ was probably capable of enhancing the immune response against the infection by the parasite, while the first parenteral application did not provide a protective effect. Therefore, the supplementary dose of $\mathrm{Zn}$ plus $\mathrm{Cu}$ in lambs experimentally infected with $H$. contortus could be recommended as a complementary therapy in order to provide better conditions for the animal to cope with this parasitic disease.

Further studies need to be carried out in order to set a more accurate dose and application intervals for sheep, aiming a better utilization of $\mathrm{Zn}$ and $\mathrm{Cu}$ against $H$. contortus.

\section{Conflict of interest}

No conflict of interest.

\section{Acknowledgments}

The authors are grateful to Fapergs for financial support for the experiment was developed.

\section{References}

Abbas, A.K., Lichtman, A.H., Pillai, S., 2012. Cellular and Molecular Immunology, 1st ed. Elsevier, Philadelphia.

Amarante, A.F.T., 2001. Controle de endoparasitoses dos ovinos. In: Mattos, W.R.S. (Ed.), A produção animal na visão dos brasileiros. Fealq/SBZ, Piracicaba, pp. 461-473.

Bambou, J.C., Gonzalez-Garcia, E., Chevrotiere, C., Arquet, R., Vachiéry, N., Mandonnet, N., 2009. Peripheral immune response in resistant and susceptible Creole Kids experimentally infected with Haemonchus contortus. Small Rumin. Res. 82, 34-39.

Bizzi, C.A., Flores, E.L.M., Nobrega, J.A., Oliveira, J.S.S., Schmidt, L., Mortari, S.R., 2014. Evaluation of a digestion procedure based on the use of diluted nitric acid solutions and $\mathrm{H}_{2} \mathrm{O}_{2}$ for the multielement determination of whole milk powder and bovine liver by ICP-based techniques. J. Anal. Atomic Spectr. 29 (2), 332-338.

Bungiro Jr., R.D., Sun, T., Harrison, L.M., Shoemaker, C.B., Cappello, M., 2008. Mucosal antibody responses in experimental hookworm infection. Parasit. Immunol. 30, 293-303.

Cho, W.S., Duffin, R., Poland, C.A., Duschl, A., Oostingh, J.G., MacNee, W., 2012. Differential pro-inflammatory effects of metal oxide nanoparticles and their soluble ions in vitro and in vivo; zinc and copper nanoparticles, but not their ions, recruit eosinophils to the lungs. Nanotoxicology 6, 22-35.

Fausto, G.C., (Dissertação) 2011. Efeito do cobre e do selenito de sódio no estresse oxidativo, proteínas séricas e carga parasitária de cordeiros infectados experimentalmente por Haemonchus contortus. Universidade Federal de Santa Maria.

Guo, H.C., Chen, P.C., Yeh, M.S., Hsiung, D.Y., Wang, C.L., 2011. Cu/Zn ratios are associated with nutritional status, oxidative stress, inflammation, and immune abnormalities in patients on peritoneal dialysis. Clin. Biochem. 44, 275-289.

Herdt, T.H., Hoff, B., 2011. The use of blood analysis to evaluate trace mineral status in ruminant livestock. Vet. Clin. N. Am. Food Animal Pract. 27, 255-283.

Lassen, E.D., Weiser, G., 2007. Tecnologia laboratorial em medicina veterinária In Hematologia e Bioquimica Clínica Veterinária. Roca. São Paulo, Brazil, pp. 3-36.

Meeusen, E.N.T., Balic, A., Bowles, V., 2005. Cells, cytokines and other molecules associated with rejection of gastrointestinal nematode parasites. Vet. Immunol. Immunopathol. 108, 121-125.

Molento, M.B., Gavião, A.A., Depner, R.A., Pires, C.C., 2009. Frequency of treatment and production performance using the FAMACHA method compared with preventive control in ewes. Vet. Parasitol. 162, 314-319

Molinaro, E.M., Caputo, L.F.G., Amendoeira, M.R.R., 2009. Conceitos e métodos para formação de profissionais em laboratórios e saúde, 1 st ed. Fiocruz, Rio de Janeiro.

Nicolodi, P.R.S.J., Camargo, E.V., Rocha, R.X., Cyrillo, F.C., Souza, F.N., Libera, A.M.M.D., Bondan, C., Leal, M.L.R., 2010. Perfil proteico e metabolismo oxidativo de cordeiros experimentalmente infectados pelo Haemonchus contortus e suplementados com selênio e vitamina E. Cienc. Rural 40, 561-567.

Oliveira, C.M.B., Sakata, R.K., Issy, A.M., Gerola, L.R., Salomão, R., 2011. Citocinas e Dor. Rev. Bras. Anestesiol. 61, 255-265.

Peixoto, P.V., Moraes, S.S., Lemos, R.A., 1994. Ocorrência da paraqueratose hereditária (linhagem letal A-46) no Brasil. Pesq. Vet. Bras. 14, 79-84.

Pocino, M., Baute, L., Malavé, I., 1991. Influence of the oral administration of excess copper on the immune response. Fundam. Appl. Toxicol. 16, 249-256

Ranjan, R., Swarup, D., Naresh, R., Patra, R.C., 2005. Enhanced erythrocytic lipid peroxides and reduced plasma ascorbic acid, and alteration in blood trace elements level in dairy cows with mastitis. Vet. Res. Commun. 29, 27-34.

Scott, M.E., Koski, K.G., 2000. Zinc deficiency impairs immune responses against parasitic nematode infections at intestinal and systemic sites. J. Nutr. 130, 1412S-1420S.

Shaw, R.J., Gatehouse, T.K., McNeil, M.M., 1998. Serum IgG responses during primary and challenge infections of sheep with Trichostrongylus colubriformis. Int. J. Parasitol. 28, 293-302.

Soli, F., Terril, T.H., Shaik, S.A., Getz, W.R., Miller, J.E., Vanguru, M., Burke, J.M., 2010. Efficacy of copper oxide wire particles against gastrointestinal nematodes in sheep and goats. Vet. Parasitol. 168, 93-96.

Ueno, H., Gonçalves, P.C., 1998. Manual for Diagnosis of Helminthiasis in Ruminants, 1 st ed. Press Color, Salvador.

Vilela, F.G., Zanetti, M.A., Saran Netto, A., Freitas Junior, J.E., Yoshikawa, C.Y.C., 2011. Biodisponibilidade de fontes orgânicas e inorgânicas de zinco em ovinos. Arq. Bras. Med. Vet. Zootec. 63, 448-455.

Zi, Y., Wu, L.R., Ting, W., Cai, Z., Hong, W.W., Huang, F.L., 2009. Influence of $\mathrm{Zn} \mathrm{Cu}$ to immunity function on poisoned sheep. Chin. J. Vet. Sci. 2, 207-209. 